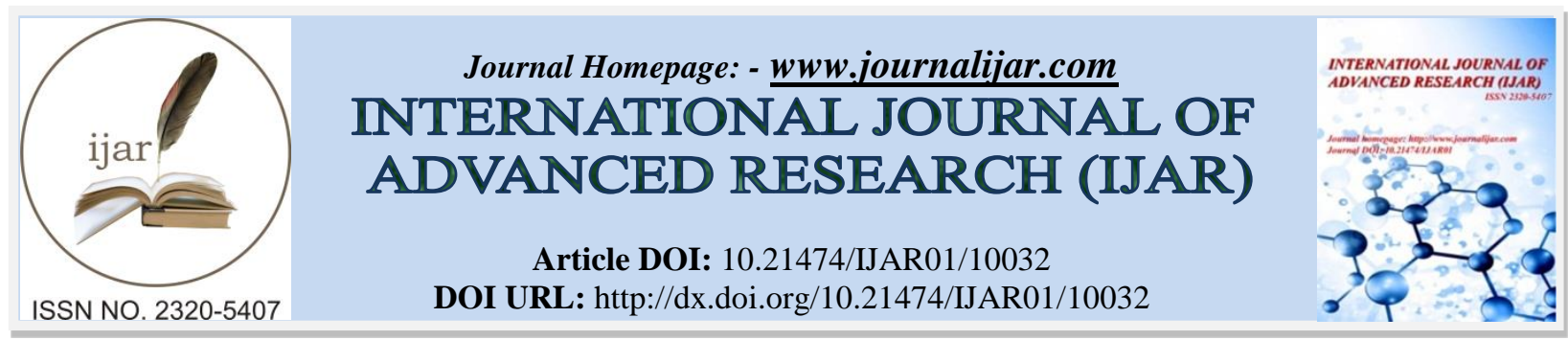

RESEARCH ARTICLE

\title{
AWARENESS, KNOWLEDGE, AND PERCEPTION OF AMBLYOPIA AMONG PARENTS ATTENDING PEDIATRIC AND OPHTHALMOLOGY CLINICS AT KASCH. RIYADH.
}

Malak Mansour Alhaddab ${ }^{1}$, Afaf Moukaddem ${ }^{2}$ and Bashaer Dabsan Albaqami ${ }^{3}$.

1. Faculty of Medicine. King Saud Bin Abdulaziz University for Health sciences. Riyadh. Saudi Arabia.

2. Faculty of Medicine Research Unit. King Saud Bin Abdulaziz University for Health sciences. Riyadh. Saudi Arabia.

3. Pediatric department. King Abdullah Specialist Children Hospital. Riyadh. Saudi Arabia.

\section{Manuscript Info}

...........................

Manuscript History

Received: 10 September 2019

Final Accepted: 12 October 2019

Published: November 2019

Key words:-

Amblyopia. awareness. knowledge. ophthalmology. pediatric. Riyadh. Saudi Arabia.

\section{Abstract}

Objective: To assess the levels of awareness. knowledge and perception of amblyopia in Saudi parents of children attending pediatrics and ophthalmology clinics at King Abdullah Specialist Children Hospital.

Methods: This study was a cross-sectional study utilizing a convenient sampling technique. Face-to-face interviews using a structured questionnaire assessed parents' knowledge of amblyopia. Data was analyzed using SPSS version22-Independent sample t-test or ANOVA were used as applicable.

Results: A total of 399 participants (40.9\% male) were included with a mean age \pm SD of $34.0 \pm 8$. Almost a third participant $(36.3 \%)$ were aware of amblyopia and $25.6 \%$ were identified the correct amblyopia definition. Additionally, refractive errors and cataract were appropriately perceived as amblyopia etiologies among $28.6 \%$ and $10.0 \%$ of the participants. Respectively, knowledge about the suitable treatment options also was low. Whereby only a quarter gave correct answers. Knowledge level was significantly higher among females compared to males $(\mathrm{p}=0.04)$, and among those being in ophthalmology clinic compared to pediatric clinic $(\mathrm{p}=0.003)$. Internet/social media and relatives/friends were the main sources of knowledge for the amblyopia-aware parents.

Conclusion: This study revealed that the awareness of the definition and causes of amblyopia was low. Also, knowledge about treatment options was inadequate. However, the perception of early detection was high. Parents need a higher level of awareness about amblyopia and this can be achieved by conducting planned educational programs and awareness campaigns. This in addition to the physician's role in educating parents about the guidelines of children vision screening.

Corresponding Author:-Malak Mansour Alhaddab.

Address:-Faculty of Medicine. King Saud Bin Abdulaziz University for Health sciences. Riyadh. Saudi Arabia. 


\section{Introduction:-}

Amblyopia is an abnormal condition in visual development that occurs in one eye and causes reduction in the function of the eye as a result of abnormal visual cortex stimulation without pathological or structural abnormalities (Wright, 2006). The reduction of visual acuity and contrast sensitivity in amblyopia is caused by abnormal visual processing of the primary visual cortex (V1) (Braverman, 2015). Amblyopia is the most common cause of vision impairment in children between birth and up to 7 years of age (Keech \& Kutschke, 1995). Also, it is one of the reasons of decreased vision in adulthood (Wu \& Hunter, 2006). According to World Health Organization (WHO), 12 million children less than 15 years old are visually impaired due to uncorrected refractive errors and amblyopia (Braverman, 2015). Uncorrected high refractive error causes about 50\% of amblyopia (Attebo et al., 1998). In addition, it can be associated with many other conditions such as anisometropia, strabismus, and unilateral or bilateral astigmatism (Ciuffreda et al., 1991). The less common causes of amblyopia in children are congenital cataract, dystrophy, and corneal injuries (Ciuffreda et al., 1991). Psychological difficulties were reported in amblyopic patients such as lack of personal confidence and depression (Hatt et al., 2006). Moreover, amblyopia negatively affects school progress, playing with other children, sport activities, and future job opportunities (AlYahya et al., 2012). The treatment of amblyopia can be useful if the therapy started as early as possible and optimally before 7 years of age while the chances of therapeutic success in older children are significantly reduced (Al-zahrani et al., 2018). Moreover, regular follow-up of the treatment is necessary in order to reach satisfactory therapeutic results (Al-zahrani et al.,2018). A study conducted in India reported that parents were aware about some vision problems such as cataract, strabismus, and refractive error, but amblyopia was the only condition with poor awareness. Also, the study showed that regarding the perception, parents perceived that food like eggs and carrots could treat the eye problem. In addition, some parents thought the strabismus was a sign of luck while the spectacle correction leads to social stigma (Senthilkumar et al., 2013). Moreover, another study conducted in India revealed that parents with higher education used the internet as main source of knowledge while parents with low education level gain knowledge from relatives and friends who are not very knowledgeable (Singh et al., 2017). Similarly, a study conducted in Nigeria found that majority of parents were aware of refractive error, cataract, and strabismus. but they had poor awareness about amblyopia (Ebeigbe \& Emedike, 2017). Also, the study showed that the parents' knowledge about the causes of vision problem were watching TV, night reading, and eating too much carbohydrate. According to the literature, it is very important that parents are aware of the amblyopia condition and they have a role in improve eye care of the child because early detection and intervention of amblyopia can be effective when done at an early age (Isawumi et al., 2014). Furthermore, a study conducted in Jeddah, Saudi Arabia, reported the majority of parents were unaware about the correct definition of amblyopia, and a small number (18.8\%) of the participants chose patching the strong eye to treat amblyopia, and other participants chose wearing glasses as a possible treatment option, while majority of participant chose eye exercise, surgery, and leaser which are wrong answers to treat amblyopia, and this showed lack of knowledge about treatment options. Also, (75\%) of participants chose wrong answer which are exposure to TV, I pad, down syndrome, stroke, and cerebral palsy as a cause of amblyopia whereas half of them went to refractive error, strabismus and cataract, and that reflect lack of knowledge about the main causes of amblyopia. The study showed that relative/friends and internet/social media were the main source of knowledge about amblyopia for the individuals (Al-zahrani et al.,2018). Further, a study conducted in Alhassa, Saudi Arabia showed that the participants have a mild to moderate knowledge level about amblyopia, and one-third of parents aware of amblyopia due to personal experience, social media, and visiting ophthalmologist. In addition, most of them were aware about the important of parents' role in amblyopia detection and prevention. Moreover, the result of study revealed a significant difference in gender, marital status, occupation, and number of children (Alshaheen \& AlOwaifeer, 2018). Moreover, a study conducted in different region of Saudi Arabia reported very low level of amblyopia awareness among the Saudi community, and because of lack of amblyopia awareness, it can lead to visual impairment among children (Alsaqr \& Masmali, 2019).

In conclusion, lack of establishing public enlightenment and health education program that regularly keep the individuals knowledgeable about the amblyopia, and lack of establishing cost-effective screening form for early detection and handling the factors that cause poor compliance to treatment lead to lateness and ineffectual treatment of amblyopia between children, so it is very important to educate parents to have enough knowledge about amblyopia and to identify symptoms that are present in their child to consult the doctor as soon as possible for necessary follow-up and to avoid negative consequences in future.

This study attempts to assess the level of parents' awareness, knowledge, and perception of amblyopia and related eye diseases in their children attending the ophthalmology and pediatric outpatient clinic in King Abdullah Specialized Children's Hospital (KASCH). National Guard Health Affairs (NGHA) - Riyadh. Saudi Arabia to 
emphasize the parents' role in early detection of amblyopia to get the satisfactory result of therapeutic treatment. Also, to provide an outline about the causes, consequences, diagnosis, and treatment of amblyopia for the parents' knowledge. The study shows demographic factors to detect the most significant conditions. Subsequently, relevant awareness programs will be conducted for the most deficient aspects.

\section{Methods:-}

\section{Study Area/Setting:}

This study was conducted at King Abdullah Specialized Children's Hospital (KASCH), in National Guard Health Affairs (NGHA) - Riyadh, Saudi Arabia. It was established in 2015, and it is the first medical referral institute for children that the Ministry of National Guard provide to be a unique addition to King Abdulaziz Medical City, Riyadh, Saudi Arabia. The participants were surveyed from ophthalmology department and pediatric department. The ophthalmology department provides exceptional high-quality eye care to infants, children, and teenagers, and delivers complete range of medical and surgical management of eye disorders. There are more than 10 pediatric ophthalmology consultants, 5 pediatric optometrists, technicians and nurses who work in the department of ophthalmology. The pediatric department includes more than 12 pediatric consultants and pediatric subspecialties.

\section{Study Subjects: \\ Inclusion criteria:}

All Saudi parents attending pediatric ophthalmology and pediatrics clinics were included.

\section{Sample Size and Technique:}

The sample size was calculated by using online calculator, Raosoft, with a margin of error 5\%. Confidence interval $95 \%$, a population of 20.000 , and a response distribution of $50 \%$ the sample size was calculated to be 377 . Nonprobability convenience sampling technique was used; all parents who agreed to participate and attended to pediatric and ophthalmology clinic were included.

\section{Data Collection Methods and Management:}

Data was collected by using a structured questionnaire developed by the author herself in Arabic language. The survey questions were designed/chosen from several published literatures (Al-zahrani et al., 2018; Alshaheen \& AlOwaifeer, 2018 ; Ebeigbe \& Emedike, 2017 ). Data was collected in four months between pediatric and ophthalmology clinics at KASCH. The questionnaire was reviewed by 3 pediatric ophthalmologists at least for content validation, and then the survey was piloted for validity and reliability purposes and internal consistency was measured using Cronbach alpha which was $=0.86$ for perception about amblyopia complications and treatment and 0.92 for perceived parents' role in amblyopia. Pilot participants gave feedback on clarity and appropriateness of the questions and their comprehension.

\section{The questionnaire is divided into 6 parts:}

1. Section one on demographic data of the participants such as: age, gender, marital status, family history of eye disease, number of children, occupation, residence... etc.

2. Section two about awareness about amblyopia detection and its diagnosis, and it was yes/no answered. For example, hearing about amblyopia; yes/ no. Amblyopia can be diagnosed by pediatric or ophthalmology doctor; yes/ no.

3. Section three about knowledge regarding amblyopia with regards to 4 dimensions including definition, possible etiologies, treatment options, and source of knowledge such as doctor, internet and social media, relatives and friends, awareness campaigns ... etc.

4. Section four on perception and attitude about amblyopia complications and treatment, and it was yes/no answered. For example, there is no treatment for amblyopia; yes/no. early treatment leads to better outcome; yes/no. Amblyopia is best treated at young age; yes/no. Amblyopia worsens if left untreated; yes/no ...etc.

5. Section five on perception and attitude about amblyopia complications and impact. It was measured in 4-point scale $(1=$ strongly disagree to $4=$ Strongly agree).

6. Section six about awareness of the role of parents in prevention and early detection, diagnosis, treatment efficacy, compliance with treatment, follow-up, psychological and social supports of the afflicted child using 5points Likert type scale $(1=$ not important at all to $5=$ very important $)$.

7. Amblyopia knowledge score (AKS) was calculated as the number of correct answers for questions relating to definition (10 items), etiology (14 items), and options of treatment (6 items) of amblyopia. 


\section{Data Analysis:-}

Statistical Package for Social Sciences (SPSS), version 22 was used to enter and analyze the data. Descriptive statistics were used to introduce participants' characteristics as well as the answers to the different questionnaire parts whereby categorical variables were presented as frequency and percentage and continuous variables as mean \pm standard deviation (SD). Due to the non-normal distribution of AKS. nonparametric Mann-Whitney test was used (for testing association between score and gender, clinics, resident) and Kruskal-Wallis test for the association of score with marital status, level of education, and occupation. P-value of $<0.05$ was considered to reject the null hypothesis and to identify the significance level.

For ethical considerations, a consent form was given to the participants to ensure their agreement. Also, both the study protocol and questionnaires were approved by KAIMRC, and participant's privacy and confidentiality were assured and respected, no identifiers were collected and all data both hard and soft copies were stored within MNGHA premises and accessed by the research team only.

\section{Results:-}

\section{Population's characteristics}

A total of 399 parents of children attending the Pediatrics (49.1\%) and Ophthalmology (50.9\%) departments were interviewed. Ages ranged from 20 to 60 years with a mean \pm SD of $34 \pm 8$ years. More than half of participants $(59.1 \%$ ) were females, $85.7 \%$ were married and $84.0 \%$ living in urban areas. The summary of the sociodemographic characteristics is shown in (Table 1).

\section{Awareness and perception about amblyopia and its diagnosis}

Almost half of the total participants (48.6\%) were unaware of what amblyopia is. One-third of participants (26.3\%) who were aware of amblyopia believed amblyopia can be detected by the naked eye, some participants (39.9\%) believed that amblyopia can be diagnosed by a GP or family doctor, and $67.2 \%$ that it can only be diagnosed by an eye specialist. Furthermore, more than half of the participants were aware that it may occur both in childhood and adulthood (Table 2).

\section{Perceptions about amblyopia complications and treatment outcomes:}

More than half of the participants (64.9\%) realize that early treatment leads to better outcomes, that amblyopia is best treated at young age $(60.4 \%)$, and that it worsens if left untreated $(57.4 \%)$. Respondents' perception was more divided regarding the possible impact and complications of amblyopia, as half of them agreed or strongly agreed that amblyopia may cause blindness, disability, stigmatization, impaired quality of life, and school failure; whereas only one-third of participants believed it can be an economic burden for the family (Table 3 ).

\section{Perceived parent's role in amblyopia management:}

Majority of the participants perceived the parents' role in amblyopia as being important or very important, particularly in the following dimensions: compliance with treatment (90.2\%); diagnosis (88.5\%); follow up (88.5\%) and early detection $(87.7 \%)$. It is worth noting that approximately $21.3 \%$ would not consider the role of parents in prevention (Table 4).

\section{Knowledge about amblyopia:}

Knowledge about the definition of amblyopia showed that only $25.3 \%$ of participants correctly identified amblyopia as being a vision loss in one eye or decreased vision in one or both eyes ; whereas $36.4 \%$ misidentified it as misalignment of the eye and $32.3 \%$ as eyes do not line up in the same direction (Figure 1). Knowledge about etiologies showed that $28.6 \%$ and $10.0 \%$ of participants correctly identified the most common etiologies of amblyopia as refractive error and cataract. While most participants misidentified maternal illness. Prematurity, fever in infancy, electronic devises usage, stroke, cerebral palsy, Down syndrome, nutrition deficiency, and trauma as etiologies of amblyopia (Figure 2). Knowledge about treatment options showed that $42.9 \%$ and $24.3 \%$ of participants correctly identified glasses and patching the strong eye as possible treatment options; whereas more than half misidentified eye muscle exercise, surgery, and laser therapy as being part of the amblyopia treatment, respectively (Figure 3). The majority of participants' sources on amblyopia was internet and social media (37.6\%) and friend and relatives (36.6\%) (Figure 4). 


\section{Factors associated with knowledge about amblyopia:}

Based on AKS. knowledge level was statistically associated with gender as it was higher among females versus males (Median. Q1-Q3 AKS = 21. 21-23 versus 21. 19-23; Mann-Whitney U test. p=0.04). It was also higher among ophthalmology clinic versus pediatric clinic (Median. Q1-Q3 AKS = 22. 21-23 versus 21. 19-23; MannWhitney $\mathrm{U}$ test. $\mathrm{p}=0.003)$. Also, marital status showed a statistically significant association with AKS ( $\mathrm{p}=0.01)$. No statistically significant association was found between AKS and family history of eye disease $(\mathrm{p}=0.96)$. residency area $(\mathrm{p}=0.12)$. occupational statues $(\mathrm{p}=0.46)$ or number of children $(\mathrm{p}=0.52)$. Similarly, knowledge source did not influence the knowledge level ( $p>0.05$ ) (Table 5).

Table 1:-Participant's characteristics. $(\mathrm{N}=399)$.

\begin{tabular}{|c|c|c|c|}
\hline Demographic Variables & & Frequency & Percentage \\
\hline Age $($ mean \pm SD) & & $34 \pm 8$ & \\
\hline Gender & $\begin{array}{l}\text { - Female } \\
\text { - Male }\end{array}$ & $\begin{array}{l}236 \\
163\end{array}$ & $\begin{array}{l}59.1 \\
40.9\end{array}$ \\
\hline Clinics & $\begin{array}{l}\text { - General Pediatric } \\
\text { - Pediatric ophthalmology }\end{array}$ & $\begin{array}{l}196 \\
203\end{array}$ & $\begin{array}{l}49.1 \\
50.9\end{array}$ \\
\hline Marital status & $\begin{array}{ll}\text { - } & \text { Married } \\
\text { - } & \text { Divorced } \\
\text { - } & \text { Widow }\end{array}$ & $\begin{array}{c}342 \\
22 \\
3\end{array}$ & $\begin{array}{c}85.7 \\
5.5 \\
0.8\end{array}$ \\
\hline Residency & $\begin{array}{ll}\text { - } & \text { Urban } \\
\text { - } & \text { Rural }\end{array}$ & $\begin{array}{c}335 \\
64\end{array}$ & $\begin{array}{l}84.0 \\
16.0\end{array}$ \\
\hline Occupation & $\begin{array}{ll} & \\
\text { - } & \text { Employed } \\
\text { - } & \text { Housewife } \\
\text { - } & \text { Unemployed } \\
& \text { Retired }\end{array}$ & $\begin{array}{l}240 \\
71 \\
73 \\
11\end{array}$ & $\begin{array}{c}60.2 \\
17.8 \\
18.3 \\
2.8\end{array}$ \\
\hline Number of children & $\begin{array}{ll}\text { - } & \text { None } \\
\text { - } & 1-2 \\
\text { - } & 3-5 \\
\text { - } & >5\end{array}$ & $\begin{array}{c}89 \\
153 \\
105 \\
52\end{array}$ & $\begin{array}{l}22.3 \\
38.3 \\
26.3 \\
13.0\end{array}$ \\
\hline Family history of eye disease & $\begin{array}{ll}- & \text { Yes } \\
\text { - } & \text { No } \\
\end{array}$ & $\begin{array}{l}154 \\
241 \\
\end{array}$ & $\begin{array}{l}38.6 \\
60.4\end{array}$ \\
\hline
\end{tabular}

Values are frequency (percentage) unless indicated otherwise; SD: standard deviation; because of missing data some values do not sum up to the total. 
Table 2:-Awareness about amblyopia and its diagnosis. $(\mathrm{N}=399)$

\begin{tabular}{|c|c|c|c|}
\hline \multirow{2}{*}{\begin{tabular}{|c|} 
Demographic Variables \\
Have you ever heard of amblyopia?
\end{tabular}} & 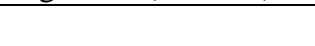 & Frequency & Percentage \\
\hline & $\begin{array}{ll} & \\
\text { - } & \text { Yes } \\
\text { - } & \text { No don't know }\end{array}$ & $\begin{array}{r}145 \\
194 \\
60\end{array}$ & $\begin{array}{l}36.3 \\
48.6 \\
15.0\end{array}$ \\
\hline \multicolumn{2}{|c|}{ Amblyopia can be detected by naked eye. } & $\begin{array}{l}105 \\
144 \\
150\end{array}$ & $\begin{array}{l}26.3 \\
36.1 \\
37.6\end{array}$ \\
\hline $\begin{array}{l}\text { Amblyopia can be diagnosed by } \\
\text { family doctor. }\end{array}$ & $\begin{array}{l}\text { General Pediatric or } \\
\text { - } \quad \text { Yes } \\
\text { - No } \\
\text { - } \quad \text { I don't know }\end{array}$ & $\begin{array}{l}159 \\
122 \\
117\end{array}$ & $\begin{array}{l}39.9 \\
30.7 \\
29.4\end{array}$ \\
\hline Amblyopia can only be diagnosed by & $\begin{array}{l}\text { y an eye specialist } \\
\text { - } \quad \text { Yes } \\
\text { - } \quad \text { No } \\
\text { - I don't know }\end{array}$ & $\begin{array}{l}268 \\
63 \\
68\end{array}$ & $\begin{array}{l}67.2 \\
15.8 \\
17.0\end{array}$ \\
\hline Who are exposed to amblyopia? & $\begin{array}{ll} & \text { Children } \\
\text { - } & \text { Adult } \\
\text { - } & \text { Both }\end{array}$ & $\begin{array}{l}52 \\
102 \\
244\end{array}$ & $\begin{array}{l}13.0 \\
25.6 \\
61.2\end{array}$ \\
\hline
\end{tabular}

Because of missing data some values do not sum up to the total.

Table 3:-Perception and attitude about amblyopia complications and treatment outcomes. $(\mathrm{N}=399)$

\begin{tabular}{|c|c|c|c|c|c|c|c|c|c|}
\hline \multirow{2}{*}{\multicolumn{2}{|c|}{ Perception about treatment outcomes }} & \multicolumn{3}{|c|}{ No (Fales) } & \multicolumn{3}{|c|}{ Yes (True) } & \multicolumn{2}{|c|}{ Do Not Know } \\
\hline & & $\mathbf{N}$ & \multicolumn{2}{|l|}{$\%$} & $\mathbf{N}$ & \multicolumn{2}{|c|}{$\%$} & $\mathbf{N}$ & $\%$ \\
\hline \multicolumn{2}{|l|}{ There is no treatment for amblyopia } & 197 & \multicolumn{2}{|l|}{49.4} & 22 & \multicolumn{2}{|l|}{5.5} & 180 & 45.1 \\
\hline \multicolumn{2}{|l|}{ Early treatment leads to better outcomes } & 49 & \multicolumn{2}{|l|}{12.3} & 259 & \multicolumn{2}{|c|}{64.9} & 91 & 22.8 \\
\hline \multicolumn{2}{|l|}{ Amblyopia is best treated at young age } & 59 & \multicolumn{2}{|l|}{14.8} & 241 & \multicolumn{2}{|c|}{60.4} & 99 & 24.8 \\
\hline \multicolumn{2}{|l|}{ Amblyopia worsens if left untreated } & 75 & \multicolumn{2}{|l|}{18.8} & 229 & \multicolumn{2}{|c|}{57.4} & 95 & 23.8 \\
\hline \multicolumn{2}{|l|}{$\begin{array}{l}\text { The cause should always be treated to } \\
\text { prevent relapse }\end{array}$} & 66 & \multicolumn{2}{|l|}{16.5} & 228 & \multicolumn{2}{|c|}{57.1} & 103 & 25.8 \\
\hline \multirow{2}{*}{$\begin{array}{l}\text { Perception about Amblyopia } \\
\text { complications and impact }\end{array}$} & \multicolumn{3}{|c|}{ Strongly disagree } & Disa & ree & Agre & & Stro & agree \\
\hline & $\mathbf{N}$ & & $\%$ & $\mathbf{N}$ & $\%$ & $\mathbf{N}$ & $\%$ & $\mathbf{N}$ & $\%$ \\
\hline Decreased visual acuity & 12 & & 3.0 & 36 & 9.0 & 186 & 46.6 & 163 & 40.9 \\
\hline Double vision & 25 & & 6.3 & 92 & 23.1 & 173 & 43.4 & 109 & 27.3 \\
\hline Blindness & 34 & & 8.5 & 124 & 31.1 & 151 & 37.8 & 90 & 22.6 \\
\hline Disability & 23 & & 5.8 & 43 & 10.8 & 215 & 53.9 & 116 & 29.1 \\
\hline Stigmatization & 35 & & 8.8 & 84 & 21.1 & 161 & 40.4 & 119 & 29.8 \\
\hline Impaired quality of life & 36 & & 9.0 & 69 & 17.3 & 187 & 46.9 & 107 & 26.8 \\
\hline Negative impact on family & 52 & & 13.0 & 112 & 28.1 & 150 & 37.6 & 85 & 21.3 \\
\hline School failure & 25 & & 6.3 & 55 & 13.8 & 186 & 46.6 & 133 & 33.3 \\
\hline Economic burden (family) & 74 & & 18.5 & 119 & 29.8 & 129 & 32.3 & 71 & 17.8 \\
\hline
\end{tabular}

Because of missing data some values do not sum up to the total. N: number; percentage; percentages are calculated on participants who declared being aware of amblyopia. 
Table 4: Perceived parents' role in amblyopia. in different dimensions.

\begin{tabular}{|c|c|c|c|c|c|c|c|c|c|c|c|}
\hline \multirow[t]{2}{*}{$\begin{array}{l}\text { Statement } \\
\text { Parents play role in }\end{array}$} & \multicolumn{2}{|c|}{$\begin{array}{l}\text { Not } \\
\text { important } \\
\text { at all }\end{array}$} & \multicolumn{2}{|c|}{$\begin{array}{l}\text { Not } \\
\text { important }\end{array}$} & \multicolumn{2}{|c|}{$\begin{array}{l}\text { Somewhat } \\
\text { important }\end{array}$} & \multicolumn{2}{|c|}{ important } & \multicolumn{2}{|c|}{ Very important } & \multirow{2}{*}{$\begin{array}{l}\mathrm{A} \\
\%\end{array}$} \\
\hline & $\mathbf{N}$ & $\%$ & $\mathbf{N}$ & $\%$ & $\mathbf{N}$ & $\%$ & $\mathbf{N}$ & $\%$ & $\mathbf{N}$ & $\%$ & \\
\hline Amblyopia prevention & 22 & 5.5 & 25 & 6.3 & 57 & 14.3 & 74 & 18.5 & 221 & 55.4 & 73.9 \\
\hline early detection & 0 & 0.0 & 11 & 2.8 & 34 & 8.5 & 102 & 25.6 & 252 & 63.2 & 88.9 \\
\hline Diagnosis & 2 & 0.5 & 10 & 2.5 & 31 & 7.8 & 100 & 25.1 & 256 & 64.2 & 89.3 \\
\hline treatment efficacy & 2 & 0.5 & 10 & 2.5 & 35 & 8.8 & 98 & 24.6 & 254 & 63.7 & 88.3 \\
\hline treatment compliance & 3 & 0.8 & 7 & 1.8 & 37 & 9.3 & 75 & 18.8 & 277 & 69.4 & 88.2 \\
\hline follow-up & 3 & 0.8 & 10 & 2.5 & 34 & 8.5 & 79 & 19.8 & 273 & 68.4 & 88.2 \\
\hline social support & 6 & 1.5 & 15 & 3.8 & 43 & 10.8 & 94 & 23.6 & 241 & 60.4 & 84 \\
\hline psychological support & 5 & 1.3 & 20 & 5.0 & 35 & 8.8 & 81 & 20.3 & 258 & 64.7 & 85 \\
\hline
\end{tabular}

A: important or very important (percentage).

Table 5:-Factors associate with knowledge about amblyopia

\begin{tabular}{|c|c|c|}
\hline Parameter & AKS (Median. Q1-Q3) & P-value \\
\hline Age & - & 0.05 \\
\hline $\begin{aligned} \text { Gender } & \\
\bullet & \text { Male } \\
\bullet & \text { Female }\end{aligned}$ & $\begin{array}{l}21.19-23 \\
21.21-23\end{array}$ & $0.04 *$ \\
\hline $\begin{array}{cl}\text { Clinic } & \\
\bullet & \text { Ophthalmology } \\
\bullet & \text { Pediatrics }\end{array}$ & $\begin{array}{l}22.21-23 \\
21.19-23\end{array}$ & $0.003 *$ \\
\hline $\begin{aligned} & \text { Marital status } \\
& \bullet \text { Single } \\
& \bullet \text { Married } \\
& \text { - } \text { Separated } \\
& \text { - } \text { Divorced }\end{aligned}$ & $\begin{array}{l}21.21-23 \\
21.20-23 \\
20.16-22 \\
19.19-21\end{array}$ & $0.01 *$ \\
\hline \begin{aligned} \multicolumn{2}{l}{ Residence } \\
\[ \quad \text { Urban } \] \\
$\bullet \quad$ Rural \end{aligned} & $\begin{array}{l}21.20-23 \\
21.19-23\end{array}$ & 0.12 \\
\hline $\begin{array}{cl}\text { Employment } \\
\qquad \quad \text { Employed } \\
\text { - Unemployed } \\
\text { - } & \text { Housewife } \\
\text { - } & \text { Retired }\end{array}$ & $\begin{array}{l}\text { 21. } 19-23 \\
21.20-23 \\
22.21-23 \\
20.18-23\end{array}$ & 0.46 \\
\hline 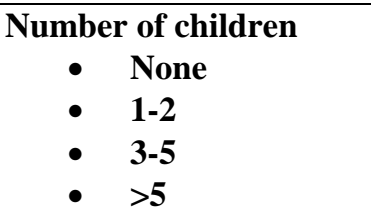 & $\begin{array}{l}\text { 21. } 21-23 \\
21.19-23 \\
21.19-23 \\
21.19-23\end{array}$ & $0.52 *$ \\
\hline
\end{tabular}




\begin{tabular}{|c|c|c|}
\hline $\begin{array}{l}\text { Family history of eye i } \\
\begin{aligned} \text { - No } \\
-\quad \text { Yes }\end{aligned}\end{array}$ & $\begin{array}{l}21.20-23 \\
22.18-23\end{array}$ & 0.96 \\
\hline \multicolumn{3}{|l|}{ Knowledge of source } \\
\hline $\begin{array}{cl}\text { Relatives/Friends } \\
\qquad \quad \text { Yes } \\
\bullet \quad \text { No } \\
\end{array}$ & $\begin{array}{l}21.19-23 \\
22.21-23 \\
\end{array}$ & $<0.001^{*}$ \\
\hline $\begin{array}{c}\text { Internet/Social Media } \\
\qquad \quad \text { Yes } \\
\cdot \quad \text { No } \\
\end{array}$ & $\begin{array}{l}21.19-23 \\
21.20-23 \\
\end{array}$ & 0.66 \\
\hline $\begin{array}{cl}\text { Doctor } & \\
\bullet & \text { Yes } \\
\bullet & \text { No } \\
\end{array}$ & $\begin{array}{l}\text { 21. } 19-23 \\
\text { 21. } 20-23 \\
\end{array}$ & 0.89 \\
\hline $\begin{array}{c}\text { Awareness campaign } \\
\qquad \quad \text { Yes } \\
\cdot \quad \text { No } \\
\end{array}$ & $\begin{array}{l}20.16-21 \\
21.20-23 \\
\end{array}$ & $0.001 *$ \\
\hline $\begin{array}{cc}\text { Books } & \\
\bullet & \text { Yes } \\
\bullet & \text { No }\end{array}$ & $\begin{array}{l}21.19-23 \\
21.20-23\end{array}$ & 0.02 \\
\hline
\end{tabular}

*P $<0.05$ declared for statistical significance. Nonparametric tests. Kruskal-Wallis and Mann-Whitney were used; Q1: 25th percentile. Q3: 75th percentile; AKS: amblyopia knowledge score.

\section{Knowledge about amblyopia definition}

Eye and brain not working well together

The two eyes dont line up in the same direction

Degeneration of optic nerve

Decreased vision in one or both eyes

Abnormal eye movement

Decreased night vision

Vision loss in one eye

Misalignment of both eyes

Inability of eye to move

Misalignment of an eye
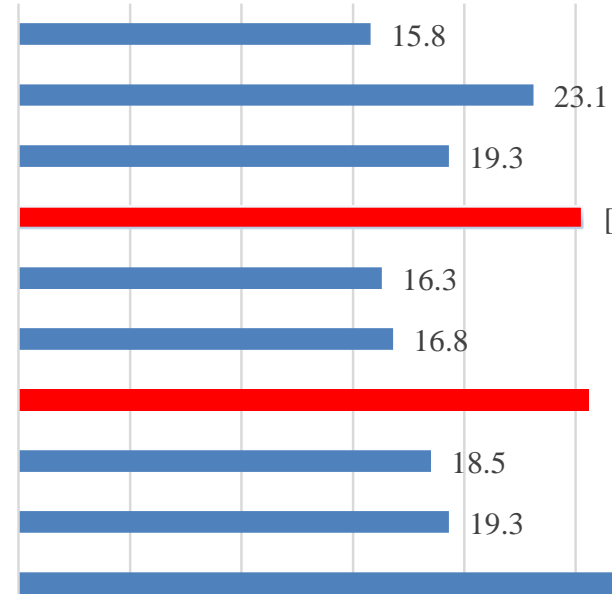

[VALUE]*

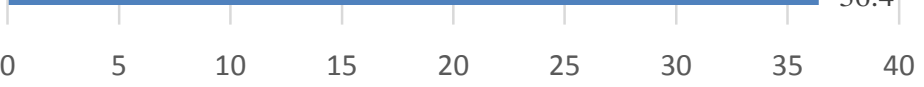

Figure 1:-knowledge about amblyopia definition. Red bars represent the correct option; Blue bar represent the false option. 


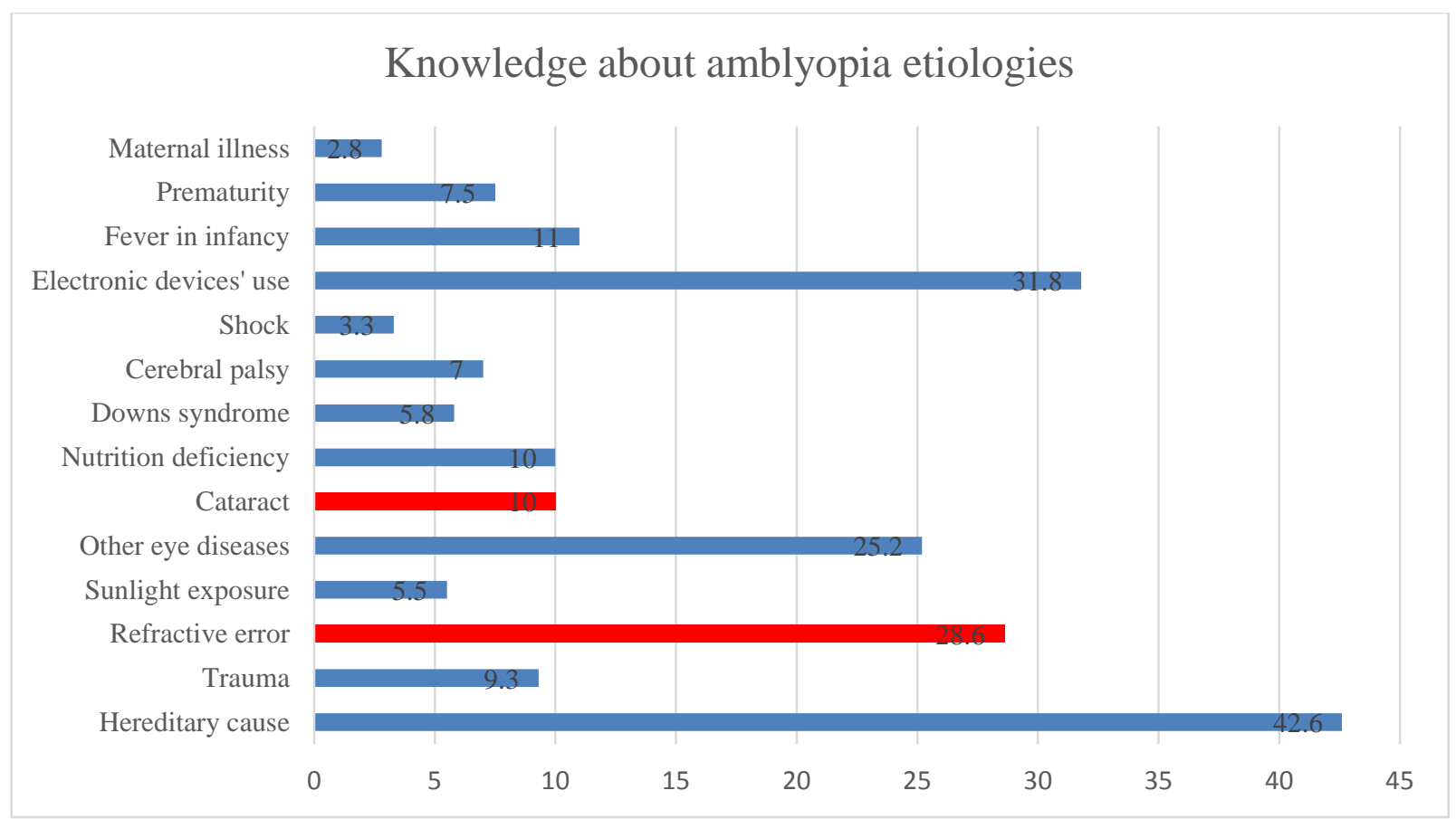

Figure 2:-knowledge about amblyopia etiologies. Red bars represent the correct option; Blue bar represent the false option.

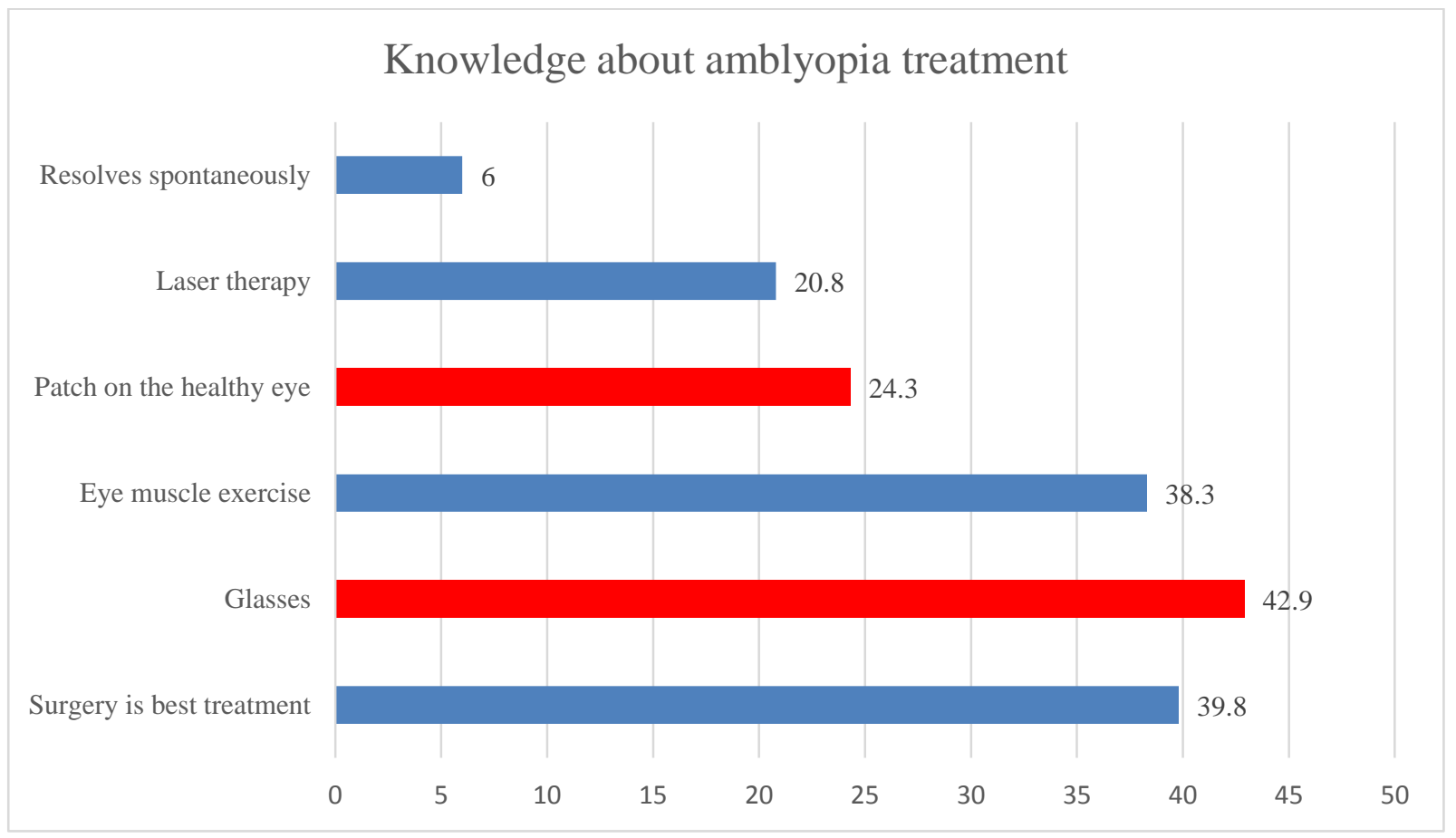

Figure 3:-knowledge about amblyopia treatment. Red bars represent the correct option; Blue bar represent the false option. 


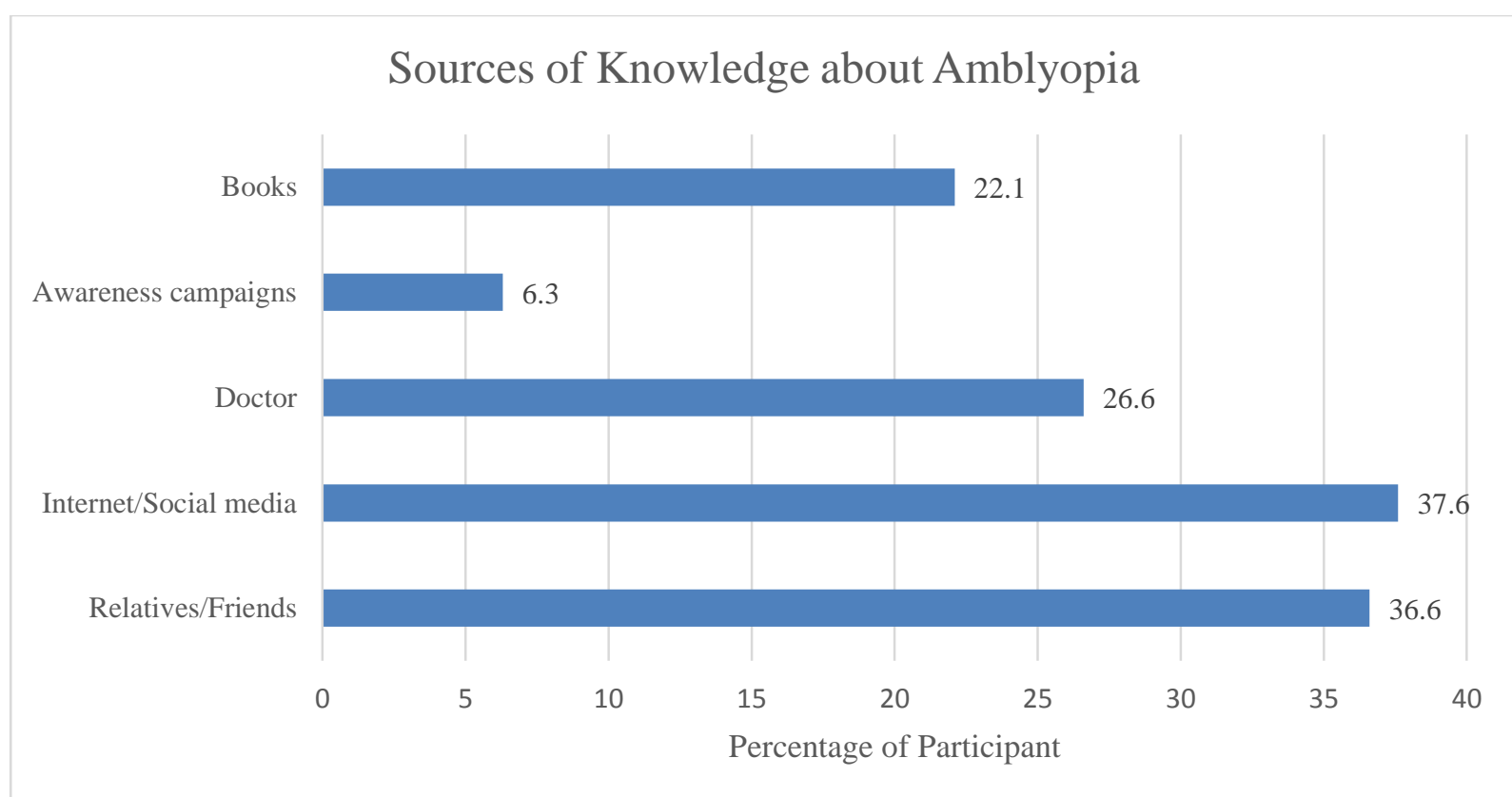

Figure 4:-Sources of knowledge about amblyopia. Bars represent the percentage of participants who declared having the given item as a source of knowledge about amblyopia.

\section{Discussion:-}

Amblyopia is one of the conditions that needs to be detected and treated early for better outcomes. also, it needs to involve ophthalmologists in the management of amblyopia. In addition, to the parents' role in complying to treatment recommended for their child's eye health. Limited public understanding of this eye condition can affect the family quality of life (Alshaheen \& AlOwaifeer, 2018; Carlton \& Kaltenthaler, 2011).

Thus, this study was conducted to reveal the parents' awareness, Knowledge, and perception of amblyopia attending ophthalmology and pediatric clinics at King Abdullah Specialist Children's Hospital (KASCH) in Riyadh through a face-to-face structured questionnaire.

In the present study, one-third of the participants were aware about amblyopia. Other local studies, include oneconducted in Jeddah assessing the awareness and perceptions of amblyopia among attendees of pediatric and ophthalmology clinics, and Alhassa assessing parents' awareness and perceptions in Alhassa region of Saudi Arabia which showed low to moderate level of awareness about amblyopia (Al-shaheen \& Al-Owaifeer, 2018; ; Al-zahrani et al.,2018).

Also, another study conducted in Jeddah evaluating the knowledge regarding common eye diseases and awareness of eye care among the Saudi population which showed only $10 \%$ of participants had heard of amblyopia as a common eye disease (Al-johani et al,.2018). Moreover, a study conducted in different regions of Saudi Arabia showed a lack of amblyopia awareness among the Saudi community (Alsaqr \& Masmali, 2019). Furthermore, the public awareness of low level of amblyopia has been previously investigated in different countries (Senthilkumar et al., 2013; Ebeigbe \& Emedike, 2017; Dirani et al., 2010 ). Poor understanding in areas such as the critical period and eye errors are evident in different parts of the world too (Newsham, 2010).

There is no significant difference in the amblyopia awareness in parents who have a family history or personal experience with eye problems especially problems that are associated with childhood. On the contrary, Nigerian study reported that only small number of parents know about amblyopia and this was positively associated with having a family history of the disease (Ebeigbe \& Emedike, 2017).

The majority of parents were unaware about the correct definition of the amblyopia. Also, parent's knowledge about the major etiologies of amblyopia like refractive error and cataract perceived low to moderate level. Similarly, a local study conducted in Jeddah showed that most of parents perceived low level of knowledge about correct 
etiologies of amblyopia. and only parents who are aware of amblyopia correctly perceived refractive errors and cataract as the major etiologies of the disease (Al-zahrani et al.,2018) In addition, a study conducted in India which considered the level of parents' awareness about vision-related diseases among children. amblyopia was the only etiology with poor awareness (Senthilkumar et al., 2013).

The awareness of amblyopia was higher in mother than fathers, this could be because mothers generally monitor their children's health more than fathers. Further, marital status was associated with awareness of amblyopia. Another local study conducted in different region of Saudi Arabia consistent with that there was a significant difference between the father and mother regarding awareness of amblyopia, and mothers had more knowledge about amblyopia when compared with fathers. Also, married participants were more aware of the term amblyopia than those with other marital statuses, including divorced and widowed participants (Alsaqr \& Masmali, 2019).

The present study revealed that relatives and friends represented the main source of knowledge about the disease. Another study showed that the role of relatives was the most significant in other eye diseases (Haddad et al,.2017). Furthermore, internet and social media contributed remarkably in the enrichment of participants' information. Other studies agreed that social media is considered a major source of information for the participants, and the patients who had better clinical outcomes received social media-based information about their disease. Also, social media such as Facebook and Twitter have the ability to increase the levels of communication among the patients each other and between healthcare professionals.(Alsaqr \& Masmali, 2019; Carlton \& Kaltenthaler, 2011; Abogunrin \& Martin 2013;Masic et al.,2012). In addition, another study mentioned that public health educators should increase awareness about amblyopia by focusing on social media and the internet to be able to reach the younger population in society (Al-johani et al., 2018; Al-Rashed et al,.2017).

The most identified complication of amblyopia was the decrease in visual acuity, disability, stigmatization, double vision, and impaired quality of life. Other studies reported that untreated amblyopia has negative impact that leads to disabling bilateral visual (Al-johani, 2018) which in turn affects patients' quality of life (Al-shaheen \& Al-Owaifeer, 2018; Carlton \& Kaltenthaler, 2011; van Leeuwen, et al., 2007).

Early detection, treatment efficacy and compliance, and follow up were the most perceived dimensions among the participants of this study. Moreover, most of the parents considered the diagnosis as either important or very important. A local study conducted in Jeddah supported these findings (Al-zahrani et al.,2018).

\section{Conclusion:-}

The present study showed indications that there is a lack of awareness and knowledge regarding amblyopia and its complications. Hence, this study emphasizes an urgent need to the establishment of fundamental guidelines. For example, implementation of visual screening programs for preschool-aged children with appropriate clinical to provide early detection and proper treatment of amblyopia. In addition, teachers could contribute as well by paying more attention to children struggling in the school, awareness days, and organizing campaigns targeting public places such as schools, malls, hospitals, and universities to elevate awareness of this disorder. Furthermore, social media, internet, and mobile applications could include advertisements and ophthalmological educational videos to help to reach a large segment of the population. Finally, a stronger doctor-patient relationship can help improve family level of awareness and knowledge and increase the children's treatment outcomes.

\section{Acknowledgment:-}

The authors would like to acknowledge their colleagues that helped in data collection (Kout Alanzi; Reem Abahusain; Tuqa Alotaibi; Ebtisam Alanzi) medical students of college of medicine.

\section{References:-}

1. Abogunrin, S., \& Martin, A. (2013): Can the Use of Social Media and Mobile Apps Improve Patient Knowledge of Disease and Health Outcomes? A Systematic Review. Value Health, 16(7): A326. 2

2. Aljohani, M., Alorabi, S., Alrajhi, Z., \& Jamjoom L. (2018): Awareness. attitudes and practices regarding common eye diseases among general population in Saudi Arabia. Ann Int Med Den Res. 4: ME01-ME4.

3. Al-Rashed, W.A., bin Abdulrahman, A.K., Zarban, A.A., Almasri, M.S., Mirza A.S., and Khandekar, R. (2017): Public Awareness regarding Common Eye Diseases among Saudi Adults in Riyadh City: A Quantitative Study. Riyadh. Jornal of Ophthalmology, 2(1-5) 
4. Alsaqr A.M., \& Masmali A.M. (2019): The Awareness of Amblyopia among Parents in Saudi Arabia. Ther Adv Ophthalmol, 51(3):1348-55

5. Alshaheen A.Y., AlOwaifeer A. M. (2018): Amblyopia: Parents' Awareness And Perceptions In Alhassa Region Of Saudi Arabia. Indo Am. J. P. Sci, 05(12): 16847-16857

6. Al-Yahya, A., Al-Odan, K., Allam, K., Al-Onazi, B., Mousa, A., \& Al-Saleh, A. A. (2012): Compliance to patching in the treatment of amblyopia. Saudi J Ophthalmol, 26(3): 305-307.

7. Alzahrani, N, Alhibshi, N, Bukhari, DMA. (2018) Awareness, perceptions and knowledge of amblyopia among pediatrics and ophthalmology clinics attendees in King AbdulAziz University Hospital, Jeddah. Int $\mathbf{J}$ of Adv Res, 6: 1506-1517.

8. Attebo, K., Mitchell, P., Cumming, R., Smith, W., Jolly, N., \& Sparkes, R. (1998): Prevalence and causes of amblyopia in an adult population. Ophthalmology, 105(1): 154-159.

9. Carlton. J. Kaltenthaler. E. (2011): Amblyopia and quality of life: a systematic review. Eye, 25(4):403

10. Ciuffreda, K. J., Levi, D. M., \& Selenow, A. (1991). Amblyopia: Basic and clinical aspects (1st ed.). Boston: Butterworth-Heinemann.

11. Dirani, M. , Yiong-Huak Chan, Gus Gazzard, Dana Marie Hornbeak, Seo-Wei Leo, Prabakaran Selvaraj, Brendan Zhou, Terri L. Young, Paul Mitchell, Rohit Varma, Tien Yin Wong, \& Seang-Mei Saw. (2010): Prevalence of refractive error in Singaporean Chinese children: the strabismus. amblyopia. and refractive error in young Singaporean Children (STARS) study. Invest Ophthalmol Vis Sci, 51(3): 1348-1355.

12. Ebeigbe, J. A., \& Emedike, C. M. (2017): Parents' awareness and perception of children's eye diseases in Nigeria. J Optom, 10(2): 104-110.

13. Haddad, M. F., Bakkar, M. M., \& Abdo, N. (2017): Public awareness of common eye diseases in Jordan. BMC Ophthalmol., 17(1): 177.

14. Hatt, S., Antonio-Santos, A., Powell, C., \& Vedula, S. S. (2006): Interventions for stimulus deprivation amblyopia. Cochrane Database Syst Rev(3): Cd005136.

15. Isawumi, M. A., Ulaikere, M., Adejumo, O. O., Adebayo, M., \& Kekunnaya, R. (2014): Awareness, perceptions and knowledge of strabismus among patients visiting a tertiary eye clinic in Southwest Nigeria. Int. Ophthalmol., 34(5): 1037-1042.

16. Keech, R. V., \& Kutschke, P. J. (1995): Upper age limit for the development of amblyopia. J. Pediatr. Ophthalmol. Strabismus, 32(2): 89-93.

17. Masic, I., Sivic, S., Toromanovic, S., Borojevic, T., \& Pandza, H. (2012): Social networks in improvement of health care. Mater Sociomed, 24(1): 48.

18. Newsham, D. (2010): The effect of recent amblyopia research on current practice in the UK. Br. J. Ophthalmol.: bjo. 2009.172015 .

19. Nilsson, J. (2007): The negative impact of amblyopia from a population perspective: untreated amblyopia almost doubles the lifetime risk of bilateral visual impairment: BMJ Publishing Group Ltd.

20. Rebecca S. Braverman. Introduction to Amblyopia. (2015): American Academy of Ophthalmology, 22(1): 8691

21. Senthilkumar, D., Balasubramaniam, S. M., Kumaran, S. E., \& Ramani, K. K. (2013): Parents' awareness and perception of children's eye diseases in Chennai, India. Optom. Vis. Sci., 90(12): 1462-1466.

22. Singh, A., Rana, V., Patyal, S., Kumar, S., Mishra, S. K., \& Sharma, V. K. (2017): To assess knowledge and attitude of parents toward children suffering from strabismus in Indian subcontinent. Indian J. Ophthalmol., 65(7): 603. 37

23. van Leeuwen, R., Eijkemans, M. J., Vingerling, J. R., Hofman, A., de Jong, P. T., \& Simonsz, H. J. (2007): Risk of bilateral visual impairment in individuals with amblyopia: the Rotterdam study. Br. J. Ophthalmol., 91(11): 1450-1451.

24. Wright, K. W. (2006). Visual Development and Amblyopia. In K. W. Wright, P. H. Spiegel \& L. S. Thompson (Eds.), Handbook of pediatric strabismus and amblyopia (2nd ed., pp. 103-137). New York: Springer.

25. Wu, C., \& Hunter, D. G. (2006): Amblyopia: diagnostic and therapeutic options. Am. J. Ophthalmol., 141(1): 175-184. 